\title{
Assessment of knowledge, attitudes and practices about tight glycemic control in the critically ill among endocrinologists and intensivists practicing in Chennai
}

\author{
Vijayaprasad Gopichandran, Shriraam Mahadevan, Latha Ravikumar, Gomathy Parasuraman, \\ Anjali Sathya, Bhuma Srinivasan, Usha Sriram
}

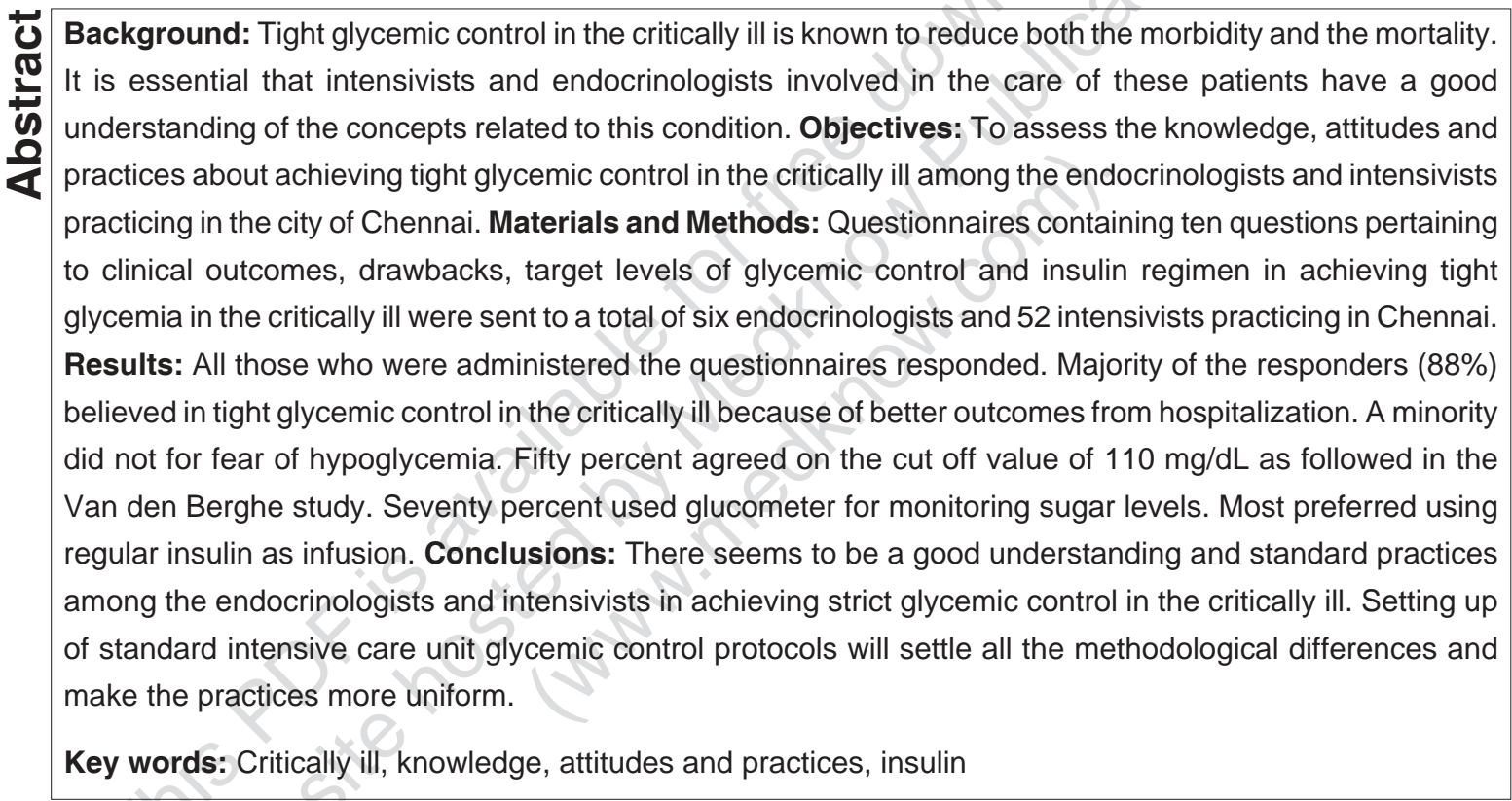

\section{Introduction}

The subject of tight glycemic control in the critically ill is of great significance. Studies have shown significant reduction in mortality and morbidity with the use of intensive insulin therapy in the critically ill. This may be due to a reduction of systemic inflammation, prevention

\footnotetext{
From:

Associates in Clinical Endocrinology Education and Research (ACEER), GEO Towers III Floor, 319, Mount Road, Chennai - 600 035, India

of immune dysfunction, protection of the endothelium and of the mitochondrial ultrastructure and function. ${ }^{[1]}$ In this scenario, it has become essential that all endocrinologists and intensivists have a clear understanding of the current guidelines for tight glycemic control in the critically ill. This questionnaire survey was conducted to assess the KAP of endocrinologists and intensivists about tight glycemic control in the critically ill.

\section{Objectives}

- To assess the KAP of endocrinologists and intensivists 
practicing in the Chennai city, about tight glycemic control in the critically ill.

- To see if there is a common consensus among the endocrinologists and among the intensivists on the various issues regarding tight glycemic control in the critically ill.

\section{Materials and Methods}

The issues relating to tight glycemic control in the critically ill were considered. Questions were prepared to address each of the following aspects.

- Clinical outcomes of maintaining tight glycemic control in the critically ill

- Adverse events related to tight glycemic control in the critically ill

- Target levels of glycemic control

- Blood sugar monitoring in the critically ill

- Insulin regimen for glycemic control in the critically ill

A total of ten questions were asked to address all these issues; at the same time the number of questions was kept limited to avoid responder disinterest.

\section{Questions}

(1) Do you believe in tight glycemic control in the critically ill?

No/Yes

(1a) If you don't believe in tight glycemic control in critical illness, please mention why?
(a) Hypoglycemia
(b) No evidence of better outcome
(c) More labor intensive
(d) Cost factor
(e) Not patient-friendly

(1b) If you believe in tight glycemic control, please mention why?
(a) Better outcome from this hospitalization
(b) Improved survival
(c) Improvement in co-morbid condition
(d) Shorter hospital stay
(e) Better wound healing
(f) Lesser long-term complications
(g) Lesser metabolic complications

(2) The plasma glucose level you aim for is:
(a) $<100 \mathrm{mg} / \mathrm{dL}$
(b) $<110 \mathrm{mg} / \mathrm{dL}$
(c) $<150 \mathrm{mg} / \mathrm{dL}$
(d) $<200 \mathrm{mg} / \mathrm{dL}$

(3) What are the methods you use for testing blood glucose control?
(a) Glucometer
(b) Finger Stick Visual Read
(c) Venous blood (Plasma Glucose)
(d) Arterial Line blood
(e) Urine glucose monitoring

(4) What methods do you use to achieve tight glycemic control?
(a) Insulin infusion
(b) Subcutaneous insulin sliding scale
(c) Frequent IV insulin boluses
(d) Basal (Glargine) + boluses
(e) $\mathrm{NPH}+$ regular insulin twice daily
(f) Oral hypoglycemic agents

(5) What type of insulin do you use for tight glycemic control in the critically ill?
(a) Human regular
(b) Animal Regular
(c) Premixed combinations
(d) $\mathrm{NPH}+$ regular OD/BD/TDS
(e) Insulin analogues like glargine/lispro

(6) What is the frequency of glucose monitoring you use?
(a) Hourly
(b) Two hourly
(c) Fourth hourly
(d) Sixth hourly
(e) Others

(7) What are the complications encountered during tight glycemic control?
(a) Hypoglycemia
(b) Fluctuations of blood glucose
(c) Electrolyte abnormalities

(8) Do you give standing orders for insulin coverage based on blood sugar levels or do you get called with blood glucose levels each time?

Standing orders/Get called

(9) Do you believe in tight glycemic control in diabetics only or in both diabetics and nondiabetics?

Diabetics only/Nondiabetics also

(10) What strategies do you follow for glycemic control when the patient is transferred from the ICU to the floors?
(a) Change to subcutaneous regular insulin
(b) Change to $\mathrm{NPH}+$ regular insulin
(c) Change to basal (Glargine) + bolus (Lispro)
(d) Change to oral hypoglycemic agents 
These questionnaires were hand delivered to six endocrinologists and fifty-two intensivists practicing in the city of Chennai to be answered and returned in a week's time. Endocrinologists were defined as physicians trained in the field of endocrinology either in India or abroad and practicing active endocrinology in the outpatient and inpatient setting. Intensivists were defined as physicians, surgeons or anesthesiologists who were currently involved in taking care of critically ill patients in intensive care units. Some of the questionnaires were also answered by postgraduate students in training in the field of intensive care. Diabetologists who were not endocrinologists were not included in the study. Among the endocrinologists, four were from large private hospitals and two were in private practice. Among the intensivists, fifty belonged to large private hospitals and teaching hospitals and two belonged to small private hospitals.

\section{Results}

The results are tabulated in Tables 1-4.

All those who were given the questionnaires responded. Some of the responders did not answer some questions. The percentage of responders who did not answer the questions was not large and so is unlikely to bring a significant change in the results. For some of the questions some physicians had selected more than one response. This is also reflected in the tables.

Majority of the responders (88\%) did believe in tight glycemic control in the critically ill. The most popular reason for the belief was "Better outcomes from this hospitalization". A very small minority of the responders did not believe in tight glycemic control and the reason for the same being incidence of hypoglycemia.

\section{Table 1: Knowledge and attitudes about tight glycemic control in the critically ill}

\begin{tabular}{|c|c|c|c|c|}
\hline Question & Response & $\begin{array}{c}\text { Endocrinologists } \\
\qquad N=6\end{array}$ & $\begin{array}{c}\text { Intensivists } \\
\mathrm{N}=52\end{array}$ & $\begin{array}{c}\text { Total } \\
\mathrm{N}=58(\%)\end{array}$ \\
\hline \multicolumn{5}{|c|}{$\begin{array}{l}\text { Do you believe in tight glycemic } \\
\text { control in the critically ill? }\end{array}$} \\
\hline & No & & 7 & $7(12)$ \\
\hline \multirow{7}{*}{$\begin{array}{l}\text { If you don't the reason for } \\
\text { the same is? }(\mathrm{N}=7)\end{array}$} & Hypoglycemia & 0 & 4 & $4(57.1)$ \\
\hline & No evidence of better out & 0 & 3 & $3(42.8)$ \\
\hline & Labor intensive & 0 & 0 & $0(0)$ \\
\hline & Not cost effective & 0 & 0 & $0(0)$ \\
\hline & Not patient friendly & 0 & 1 & $1(14.3)$ \\
\hline & Difficult logistics of frequent & & & \\
\hline & testing and maintaining insulin infusion & 0 & 1 & $1(14.3)$ \\
\hline If you do, the reason for & Better outcome from this hospitalization & 4 & 40 & $44(86.3)$ \\
\hline \multirow{6}{*}{ the same is? $(N=51)$} & Better survival & 3 & 3 & $6(11.7)$ \\
\hline & Improvement in co-morbid conditions. & 3 & 0 & $3(5.8)$ \\
\hline & Shorter hospital stay & 3 & 0 & $3(5.8)$ \\
\hline & Better wound healing & 1 & 1 & $2(3.9)$ \\
\hline & Lesser long-term complications & 1 & 1 & $2(3.9)$ \\
\hline & Lesser metabolic complications & 1 & 1 & $2(3.9)$ \\
\hline
\end{tabular}

Table 2: Knowledge, attitudes and practices on glucose levels and glucose monitoring in the critically ill

\begin{tabular}{|c|c|c|c|c|}
\hline Question & Response & $\begin{array}{l}\text { Endocrinologists } \\
\qquad N=6\end{array}$ & $\begin{array}{l}\text { Intensivists } \\
\qquad N=52\end{array}$ & $\begin{array}{c}\text { Total } \\
N=58(\%)\end{array}$ \\
\hline The target glucose levels that you & $<100 \mathrm{mg} / \mathrm{dL}$ & 1 & 4 & $5(8.6)$ \\
\hline \multirow[t]{4}{*}{ aim for in the intensive care unit are? } & $<110 \mathrm{mg} / \mathrm{dL}$ & 4 & 27 & $31(53.4)$ \\
\hline & $<150 \mathrm{mg} / \mathrm{dL}$ & 0 & 14 & $14(24.1)$ \\
\hline & $<200$ mg/dL & 0 & 5 & $5(8.6)$ \\
\hline & No Response & 1 & 2 & 3 \\
\hline The method used for monitoring & Glucometer & 5 & 36 & $41(70.7)$ \\
\hline \multirow[t]{5}{*}{ sugar levels in the critically ill is? } & Finger stick visual read & 0 & 2 & $2(3.4)$ \\
\hline & Venous plasma glucose & 6 & 10 & $16(27.6)$ \\
\hline & Arterial line, plasma glucose & 2 & 2 & $4(6.9)$ \\
\hline & Urine glucose monitoring. & 0 & 0 & $0(0)$ \\
\hline & No Response & 0 & 2 & 2 \\
\hline \multirow[t]{6}{*}{ Frequency of glucose monitoring is? } & Hourly & 5 & 5 & $10(17.2)$ \\
\hline & Two hourly & 2 & 22 & $24(41.4)$ \\
\hline & Fourth hourly & 2 & 12 & $14(24.1)$ \\
\hline & Sixth hourly & 0 & 9 & $9(15.5)$ \\
\hline & Others & 0 & 2 & $2(3.4)$ \\
\hline & No Response & 0 & 2 & 2 \\
\hline
\end{tabular}


Table 3: Knowledge, attitudes and practices on glucose control methods in the intensive care unit setting and while transferring to the floors

\begin{tabular}{|c|c|c|c|c|}
\hline Question & Response & $\begin{array}{l}\text { Endocrinologists } \\
\qquad N=6\end{array}$ & $\begin{array}{c}\text { Intensivists } \\
N=52\end{array}$ & $\begin{array}{c}\text { Total } \\
N=58(\%)\end{array}$ \\
\hline The method used for achieving tight & Insulin infusion & 6 & 31 & $37(63.8)$ \\
\hline \multirow[t]{6}{*}{ glycemic control in the critically ill is? } & Subcutaneous insulin sliding scale & 1 & 12 & $13(22.4)$ \\
\hline & Frequent IV insulin boluses & 1 & 0 & $1(1.7)$ \\
\hline & Basal (Glargine) + Boluses & 1 & 4 & $5(8.6)$ \\
\hline & $\mathrm{NPH}+$ regular insulin BD dose & 0 & 0 & $0(0)$ \\
\hline & Oral hypoglycemic agents & 0 & 0 & $0(0)$ \\
\hline & No response & 0 & 5 & 5 \\
\hline What type of insulin is used in the & Human regular & 6 & 39 & $45(77.6)$ \\
\hline \multirow[t]{5}{*}{ critically ill? } & Animal (Bovine/Porcine) regular & 0 & 0 & $0(0)$ \\
\hline & Premixed combinations & 0 & 1 & $1(1.7)$ \\
\hline & $\mathrm{NPH}+$ regular & 0 & 1 & $1(1.7)$ \\
\hline & Glargine + lispro & 0 & 2 & $2(3.4)$ \\
\hline & No response & 0 & 9 & 9 \\
\hline What strategy do you follow for & insulin & 0 & 26 & $26(44.8)$ \\
\hline glycemic control when the patient is & Change to intermediate + regular insulin & 6 & 18 & $24(41.3)$ \\
\hline transferred from the ICU to the floors? & Change to glargine + Lispro & 0 & 4 & $4(6.8)$ \\
\hline Change to subcutaneous regular & Change to oral hypoglycemic agents & 0 & 4 & $4(6.8)$ \\
\hline
\end{tabular}

Table 4: Knowledge, attitudes and practices on the practical aspects and complications of tight glycemic control in the critically ill

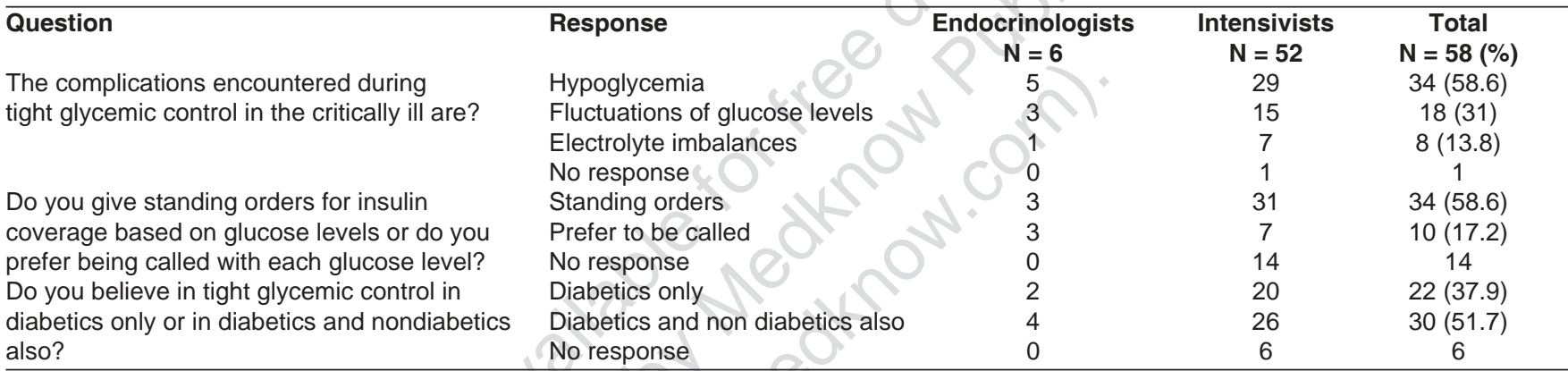

A little over half of the responders (53.4\%) agreed on the cut off value of $110 \mathrm{mg} / \mathrm{dL}$ as followed in the Greet Van Den Berghe study. The next most popular cut off was $150 \mathrm{mg} / \mathrm{dL}$. Most of the responders (70.7\%) voted for the glucometer as the method of monitoring the sugar levels. There was considerable variation in the choices for frequency of the monitoring tests.

As far as the methods used for glycemic control were concerned, insulin infusion was the most popular choice and human regular insulin was the type of insulin voted for. There was considerable variation in the method adopted while transferring the patient from the critical care unit to the floors.

Hypoglycemia was opted as the important complication during tight glycemic control by $58.6 \%$ of the responders. Standing orders for insulin dosage was the more popular method among the endocrinologists and the intensivists. The fact that tight glycemic control is not only important for diabetics but also for nondiabetics is agreed upon by $51.7 \%$ of the responders.

\section{Discussion}

Hyperglycemia is a common occurrence in critical illness and previously used to be dismissed as stress hyperglycemia. While the diabetics who present with this problem are treated, many times the nondiabetics are not considered for treatment. Van Den Berghe et al. have shown clearly that normalization of blood sugars in critically ill patients in the surgical ICU with insulin infusion regimens significantly reduces morbidity and mortality. ${ }^{[1]}$ The recent paper by the same author has looked into the same scenario in the medical ICU. This study has again shown that irrespective of their previous diabetic status, all critically ill patients benefited from intensive insulin regimen in terms of morbidity benefits. It was shown that the in hospital stay and ICU stay were reduced, weaning from the ventilator was quicker and onset of new organ damage was also lesser. ${ }^{[2]}$ In both the 
studies of intensive insulin infusion by Van den Berghe et al., the target sugar level was set at $110 \mathrm{mg} / \mathrm{dL}$. This level has shown to provide significant benefits.

Whether the high glucose level is the toxic agent and its control gives the benefit or whether insulin with its anabolic effects is the protective agent is a point of constant debate. In one study by Finney et al., it was shown that increased insulin administration was associated with increased mortality irrespective of the sugar levels. Thus the study concluded that control of the sugar levels was the protective factor rather than the insulin dose administered. This study also suggested that the upper limit for glucose is $145 \mathrm{mg} / \mathrm{dL}$ below which mortality benefits increased. ${ }^{[3]}$ There are several hypotheses to explain the protective effect of tight glycemic control in the critically ill with insulin infusion protocol. One hypothesis proposes that immune dysfunction is prevented by preventing hyperglycemia. ${ }^{[4]}$ The intensive insulin infusion protocol is said to have an antiinflammatory action on the system which is said to provide morbidity and mortality benefit. ${ }^{[5]}$ There is one hypothesis which argues that intensive insulin therapy protects against endothelial damage. ${ }^{[6,7]}$ The insulin infusion is also said to protect the mitochondrial ultrastructure and function. ${ }^{[8]}$ In another study conducted by Mesotten et al., it was shown that restoration of serum lipid profile abnormalities significantly contributed to the mortality benefits in patients on intensive insulin therapy during critical illness. ${ }^{[9]}$

With this scenario in the background we assessed the KAP among the endocrinologists and intensivists about tight glycemic control in the critically ill. From this study it was observed that there was an overall consensus among the endocrinologists and the intensivists that tight glycemic control is essential in the critically ill. They also had a sound understanding of the reasons for using tight glycemic control and its benefits. There was a good awareness about the complications of this process of tight glycemic control. The endocrinologists and the intensivists also agreed on the fact that irrespective of their diabetic status all critically ill patients required intensive insulin therapy for achieving this target. The main points of disagreement were in the methodology of glucose monitoring and the type of insulin regime once the patients were shifted to the floors.

The probable reason for this good understanding and standard practices among the endocrinologists and intensivists is the immense popularity of the Van den Berghe articles and its frequent discussion in several forums. Also noteworthy is the high prevalence of diabetes in India and a general interest among the physicians about diabetes and glycemia-related issues. Further, critical care as a separate specialty is now evolving in our country and the physicians involved in it are keeping themselves updated in the recent developments. The methodological differences are more practical in nature, which is bound to happen in the milieu of wide differences in hospital policies and practices. The authors conclude that meetings among endocrinologists and intensivists and setting up of standard ICU glycemic control protocols will make the practices more uniform.

\section{References}

1. Van Den Berghe G, Wouters P, Weekers F, Verwaest C, Bruyninckx $F$, Schetz M, et al. Intensive insulin therapy in critically ill patients. N Engl J Med 2001;345:1359-67.

2. Van Den Berghe G, Wilmer A, Hermans G, Meersseman W, Wouters PJ, Milants I, et al. Intensive insulin therapy in the medical ICU. N Engl J Med 2006;354:449-61.

3. Finney SJ, Zekveld C, Elia A, Evans TW. Glucose Control and Mortality in Critically III Patients. JAMA 2003;290:2041-7.

4. Weekers F, Giulietti AP, Michalaki M, Coopmans W, Van Herck E, Mathieu C, et al. Metabolic, endocrine and immune effects of stress hyperglycemia in a rabbit model of prolonged critical illness. Endocrinology 2003;144:5329-38.

5. Hansen TK, Thiel S, Wouters PJ, Christiansen JS, Van den Berghe G. Intensive insulin therapy exerts anti-inflammatory effects in critically ill patients and counteracts the adverse effect of low mannose-binding lectin levels. J Clin Endocrinol Metab 2003;88:1082-8.

6. Van den Berghe $\mathrm{G}$. How does blood glucose control with insulin save lives in intensive care? J Clin Invest 2004;114:1187-95.

7. Langouche L, Vanhorebeek I, Vlasselaers D, Vander Perre S, Wouters PJ, Skogstrand K, et al. Intensive insulin therapy protects the endothelium of critically ill patients. J Clin Invest 2005;115:2277-86.

8. Vanhorebeek I, De Vos R, Mesotten M, Wouters PJ, De Wolf-Peeters C, Van den Berghe G. Protection of hepatocyte mitochondrial ultrastructure and function by strict blood glucose control with insulin in critically ill patients. Lancet 2005;365:53-9.

9. Mesotten D, Swinnen JV, Vanderhoydonc F, Wouters PJ, Van den Berghe $\mathrm{G}$. Contribution of circulating lipids to the improved outcome of critical illness by glycemic control with intensive insulin therapy. J Clin Endocrinol Metab 2004;89:219-26.

Source of Support: Nil, Conflict of Interest: None declared. 